\title{
Source of ATP, ADP, AMP and Adenosine Released from Isolated Rat Caudal Artery Exposed to Noradrenaline
}

\author{
Michio Hashimoto, "Kazumasa ShinozukA*, Yasuakira TANAKA, \\ Masaaki HondA $^{* * *}$, Yukisato IsHIDA***, Richard A. BJuR ${ }^{* *}$, \\ David P. Westfall**, Keisuke Hattori* and Sumio Masumura \\ Department of Physiology, *Department of Pharmacology and ${ }^{* * *}$ The 4th \\ Department of Internal Medicine, Shimane Medical University, Izumo 693, \\ Shimane, Japan ${ }^{* * * *}$ Mitsubishi Kasei Institute of Life Sciences, Machida, \\ Tokyo 194, Japan **Department of Pharmacology, University of Nevada School \\ of Medicine, Reno, Nevada, 89557-0046, USA
}

\begin{abstract}
Purines of ATP, ADP, AMP and adenosine released from rat caudal artery with and without endothelium and the isolated smooth muscle and endothelial cells were examined, in order to determine the source. Treatment of intact segments of caudal arteries with noradrenaline $(10 \mu \mathrm{M})$ for 3 min induced a large release of ATP, ADP, AMP and adenosine. However, if the artery segments had been denuded of their endothelial lining, noradrenaline induced only a slight release of purines. Endothelial cells in primary culture prepared from caudal arteries, when exposed to noradrenaline for 3 min released large amounts of purines, whereas vascular smooth muscle cells prepared similarly and passaged endothelial cells did not release purines upon exposure to noradrenaline. These results indicate that, of smooth muscle and endothelial cells of the vascular wall, only intact endothelial cells react to $\alpha$ adrenoceptor stimulation by releasing adenine nucleotides and adenosine.
\end{abstract}

Key Words : ATP-rat caudal artery-endothelial cells-smooth muscle cells- $\alpha$-adrenoceptor

\section{Introduction}

Adenine nucleosides and nucleotides are released from extraneuronal sites as a consequence of $\alpha$-adrenoceptor stimulation in vitro blood vessel preparations (Westfall et al., 1987 ; Sedaa et al., 1990 ; Shinozuka et al, 1991 ; Ishii et al., 1993), vas deferens and ileum (Katsuragi et al., 1990). Sedaa et al., (1990) suggested that the main source of these purines released by $\alpha$-adrenoceptor stimulation of the rabbit aorta is the endothelium and a minor source is vascular smooth muscle. Indeed, Milner et al. (1990) and Bodin et al., (1991) showed that ATP is released from isolated endothelial cells of rabbit aorta by shear stress. However, an $\alpha-$ adrenoceptor stimulation has been also reported to produce ATP release from smooth muscle 
cells such as the vas deferens of the guinea pig (Katsuragi et al., 1990). These results prompted us to clarify whether ATP release from smooth muscle cells of blood vessels would be induced by the stimulation. We report here that stimulation with noradrenaline of isolated endothelial cells in primary culture and intact segments of arteries prepared from rat caudal arteries release large amounts of adenine nucleotides and adenosine.

\section{Materials and Methods}

Female Wistar rats (5 weeks old) were anesthetized with sodium pentobarbital $(50 \mathrm{mg} / \mathrm{Kg}$ $i v$ ) and exsanguinated. The caudal artery was dissected from the tail, cleaned of connective tissue and suspended in a water-jacketed organ chamber containing $2.0 \mathrm{ml}$ of a modified Krebs solution at $37^{\circ} \mathrm{C}$. The solution was continuously bubbled with $95 \% \mathrm{O}_{2}$ and $5 \% \mathrm{CO}_{2}$. The composition of the solution was as follows $(\mathrm{mM}): \mathrm{NaCl} 110 ; \mathrm{KCl} 4.6 ; \mathrm{CaCl}_{2} 2.5 ; \mathrm{NaHCO}_{3}$ $24.8 ; \mathrm{KH}_{2} \mathrm{PO}_{4} 1.2 ; \mathrm{MgSO}_{4} 1.2$; glucose 5.6. For some experiments, the endothelium of the arteries was removed by gently rubbing the endothelial surface with a cotton pellet. Arteries were allowed to equilibrate for $60 \mathrm{~min}$ and the medium was replaced every $3 \mathrm{~min}$ during the latter half of the equilibration period. After the $60 \mathrm{~min}$ equilibration period, a $3 \mathrm{~min}$ sample (which was used to determine spontaneous release) was collected by draining the organ chamber. The tissue was then stimulated with noradrenaline $(10 \mu \mathrm{M})$ for $3 \mathrm{~min}$ and the bathing solution was collected. The samples were processed for determination of ATP, ADP, AMP and adenosine by high performance liquid chromatography (HPLC)-fluorescence detection as described in detail previously (Mohri, et al., 1993). Noradrenaline bitartrate salt was obtained from Sigma (St. Louis, MO., USA).

In order to establish endothelial cell cultures and vascular smooth muscle cell cultures, caudal arteries were excised from ether-anesthetized rats. The arteries were rinsed five times in Dulbeco's modified Eagle's medium (DMEM) which contained antibiotics (100 U/ml penicillin, $100 \mu \mathrm{g} / \mathrm{ml}$ streptomycin) and an antifungal agent $(0.25 \mu \mathrm{g} / \mathrm{ml}$ fungizone). Endothelial cells were separated and cultured in individual wells of collagen plates (Celltight $\mathrm{C}-1$, Sumitono Bakelite Co., Ltd., Osaka, Japan) according to previously described methods (Hashimoto, et al., 1991 and 1992). Smooth muscle cells, which were separated by the explantation technique described by Ross with some modifications (Ross, 1971; Ohoka, et al, 1990), were treated with the same agents as described above and examined under the same conditions. These cells were cultured for 5 days with renewal medium exchanged every 2 days. For some experiments, when the endothelial cells were grown to confluency, the primary culture of endothelial cells were harvested using $0.05 \%$ trypsin and $0.01 \%$ EDTA and then further passaged. The endothelial cells were characterized by immunoperoxidase staining system using monoclonal antibodies against Factor VIII related antigen (a Biomeda Histo Scan Kit, COSMO BIO Co., Ltd., Tokyo, Japan) and by their uptake of DiI-Ac-LDL (Biomedical Technologies, Inc., Stoughton, MA, USA). Immunocytochemical characterization of the smooth muscle cells was performed using monoclonal antibodies against smooth muscle $\alpha$-actin (Sigma Chemical Co., ST. Louis, MO, USA). The smooth muscle cells showed positive staining for $\alpha$-actin but undetectable staining for Factor VIII related antigen. For some experiments, a primary culture of endoth- 
elial cells were harvested and then further passaged as previously described (Hashimoto, et al., 1992).

For experiments to evaluate the release of purines, the cultured cells $\left(20-25 \times 10^{4}\right.$ cells $/ 35$ $\mathrm{mm}$ dish for endothelial cells, $25-30 \times 10^{4}$ cells $/ 35 \mathrm{~mm}$ dish for smooth muscle cells) in collagen dishes, were washed in the modified Krebs solution and then incubated in $2 \mathrm{ml}$ of Krebs solution for $60 \mathrm{~min}$ at $37^{\circ} \mathrm{C}$ in a $95 \%$ air $/ 5 \% \mathrm{CO}_{2}$ atmosphere. After this equilibration period, $200 \mu 1$ of the bathing solution (prestimulation sample) was collected, the endothelial cells were stimulated with noradrenaline $(10 \mu \mathrm{M})$ for $3 \mathrm{~min}$ and the solution (stimulation sample) was collected. The collected solutions were then processed for the determination of ATP, ADP, AMP and adenosine by HPLC-fluorescence detection.

Data are expressed as means and standard errors of the mean (S.E.M.). Results were analyzed by Student's $t$-test for paired observations, with $\mathrm{p}<0.05$ taken as indicative of a statistically significant difference.

\section{Results}

\section{Intact and denuded artery}

The spontaneous release of ATP, ADP, AMP and adenosine from intact segments of caudal artery during 3 min was $0.116 \pm 0.027,0.146 \pm 0.022,0.184 \pm 0.049$ and $0.718 \pm 0.062 \mathrm{pmol} /$ mg wet weight, respectively. As illustrated in Fig. 1A, stimulation of the arteries with $10 \mu \mathrm{M}$

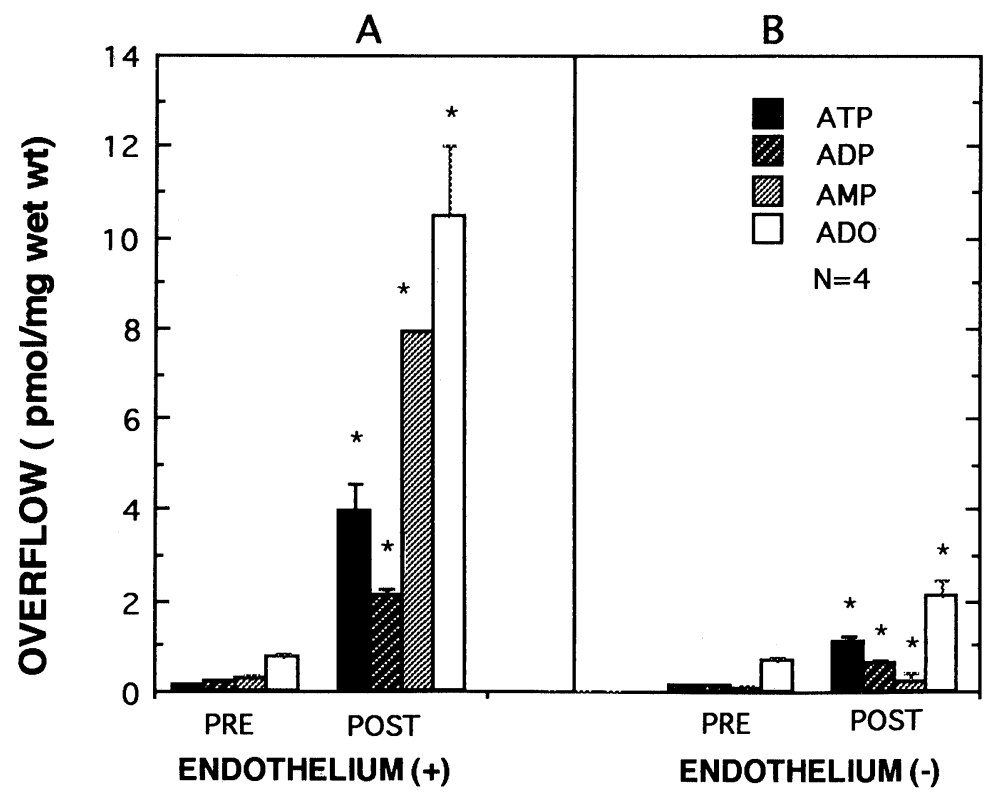

Fig. 1. Release of purine compounds from rat caudal artery with (panel A) and without (panel B) endothelium before (PRE) and after (POST) stimulation with noradrenaline (10 $\mu \mathrm{M})$. Shown are the amounts of each purine released from the caudal artery during 3 min. *indicates a significant increase above prestimulation values. $\mathrm{ADO}$, adenosine. $\mathrm{N}=$ the number of rats. 
noradrenaline for $3 \mathrm{~min}$ produced a robust release of all purines determined. $1 \mu \mathrm{M}$ isoproterenol, $\beta$-adrenoceptor agonist, did not evoke a release of adenine nucleotides and adenosine from the caudal artery at all (data not shown). On the other hand, in artery segments in which the endothelium was removed, the noradrenaline-induced release of the purines was modest, being only approximately $20 \%$ of that of intact arteries (Fig. 1B). Upon stimulation of noradrenaline, the amount of released adenosine appeared to be greater than that of ATP in the intact and denuded arteries. These findings support the idea that endothelial cells are a source of adenine nucleotides and adenosine released by $\alpha$-adrenoceptor stimulation.

\section{Endothelial and smooth muscle cells in primary culture}

Isolated endothelial cells were cultured for 5 days (primary culture) and were subjected to the experiments. The spontaneous release of ATP, ADP, AMP and adenosine from primary cultured cells for $60 \mathrm{~min}$ was $0.287 \pm 0.141,0.131 \pm 0.060,0.336 \pm 0.146$ and $0.0759 \pm 0.0052 \mathrm{pmol} / 10^{4}$ cells, respectively. As illustrated in Fig. 2A, stimulation of these cells with $10 \mu \mathrm{M}$ noradrenaline for 3 min enhanced a release of each of the four purines, with ATP being released in the greatest amounts. In terms of the amount of released purines by the noradrenaline stimulation, ATP was dominant and adenosine was smallest.

Smooth muscle cells in primary culture (for 7 days) released adenine nucleotides and adenosine spontaneously (Fig. 2B), but the amounts were less than that released from endoth-

A

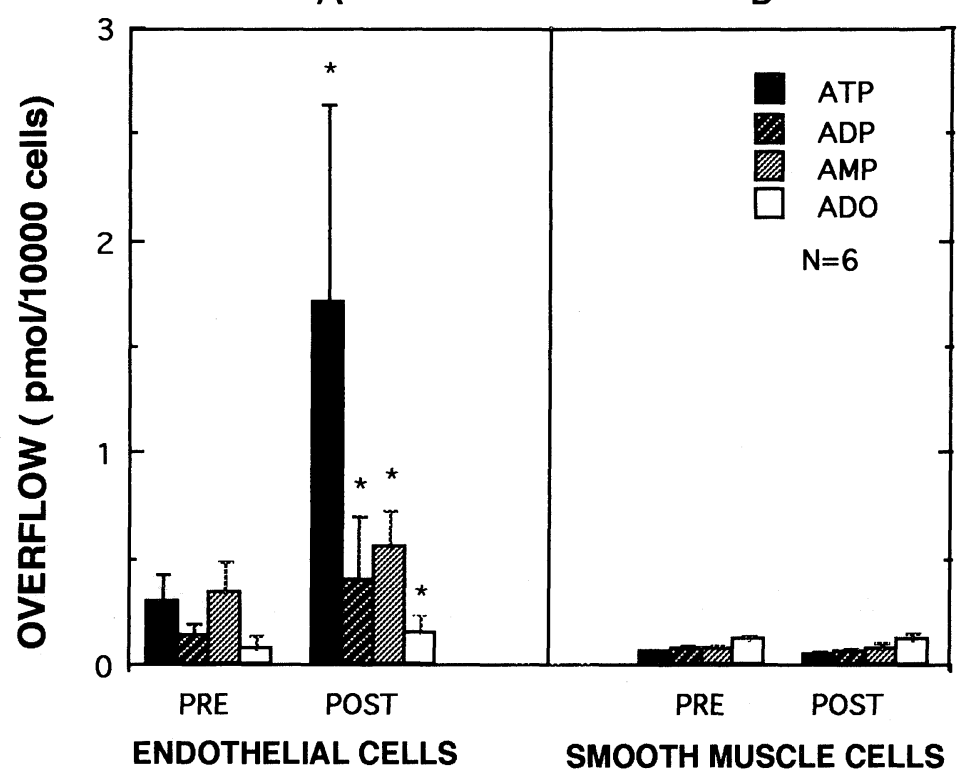

Fig. 2. Release of purine compounds from isolated endothelial cells (panel A) and isolated smooth muscle cells (panel B) before (PRE) and after (POST) stimulation with noradrenaline (10 $\mu \mathrm{M})$. Shown are the amounts of each purine released from the cell during $3 \mathrm{~min}$. *indicates a significant increase above prestimulation values. ADO, adenosine. $\mathrm{N}=$ the number of rats. 


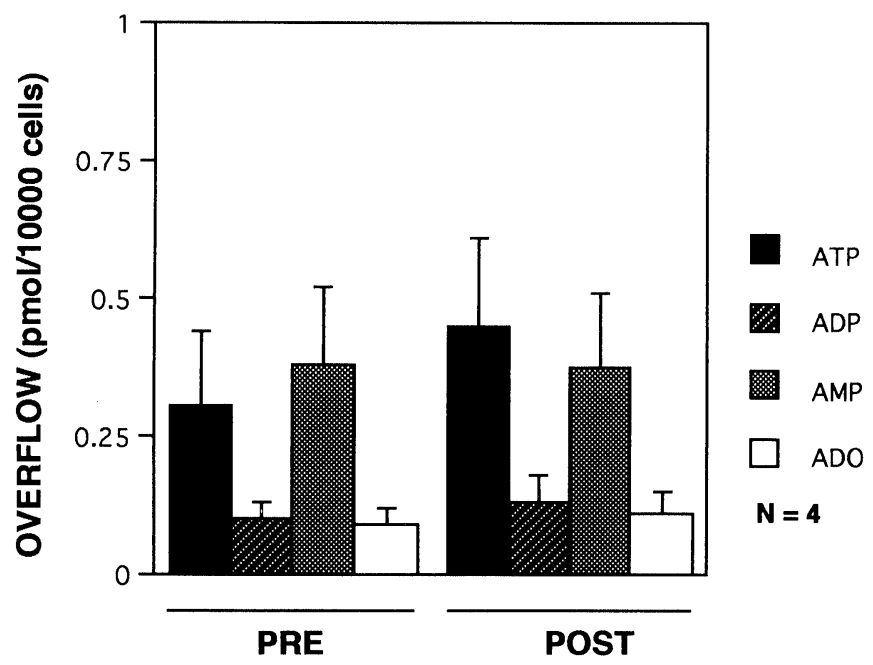

Fig. 3. Release of purine compounds from the passaged endothelial cells before (PRE) and after (POST) stimulation with noradrenaline $(10 \mu \mathrm{M})$. Shown are the amounts of each purine released from the cell during $3 \mathrm{~min}$. ADO, adenosine. $\mathrm{N}=$ the number of rats.

elial cells. Unlike endothelial cells in primary culture, however, exposure to noradrenaline for $3 \mathrm{~min}$ at $10 \mu \mathrm{M}$ did not increase the release of purines (Fig. 2B).

\section{Cultured endothelial cells once passaged}

The effect of passage in culture on the release from endothelial cells was investigated (Fig. 3). After primary-cultured cells were grown to confluency, they were once passaged and cultured for another 7 days. The passaged endothelial cells released purines in a similar quantity to those of primary-cultured cells. However, when the passaged cells were exposed to $10 \mu \mathrm{M}$ noradrenaline for $3 \mathrm{~min}$, there was no increase in the release of purines determined.

\section{Discussion}

Sedaa et al. (1990) suggested that a major source of adenine nucleotides and adenosine released by $\alpha$-adrenoceptor stimulation of rabbit aorta was the endothelial cell layer and that the smooth muscle was a minor source of the released purines. The work reported herein indicates directly that the same situation exists for the rat caudal artery. Segments of caudal artery with an intact endothelium released substantial amounts of purines in response to noradrenaline, whereas arteries denuded of endothelium released considerably less purines upon $\alpha$-adrenoceptor stimulation. Using primary cultured cells, it is clearly shown that endothelial cells, but not smooth muscle cells are stimulated by noradrenaline to release ATP and its congeners.

When cultured endothelial cells were only once passaged, they lost the ability to respond to noradrenaline in release of purines. It is difficult from the present experiments to elucidate the exact reasons why the purine release by $\alpha$-adrenoceptor stimulation disappeared in the 
passaged endothelial cells. As suggested by Ryan et al (1980), the isolation and passaging of endothelial cells by the use of trypsin may contribute to accelerated aging in vitro: loss of surface enzymes and alterations in the functions.

Among determined purines released by $\alpha$-adrenoceptor stimulation, adenosine was dominant in the intact caudal artery, but ATP was dominant in the primary cultured endothelial cells. As ATP is degraded fairly rapidly to ADP, AMP and adenosine in vascular tissues, probably through hydrolysis by ectonucleotidases (Sedaa et al., 1990 ; Slakey et al., 1990), the origin of released purine is considered to be ATP. Presumably, the activity of ectonucleotidases is higher in the intact arteries than in the cultured endothelial cells, leading to the relatively rapid degradation of ATP to adenosine in the intact tissue. Gordon et al. $(1986,1989)$ suggested that the degradation of ATP to adenosine by ectonucleotidase on cultured endothelial cell is not very rapid but that on cultured smooth muscle cell is rapid.

Given the large capacity of the endothelium of blood vessels to release the adenine nucleotides and adenosine, one wonders what functions these extracellular purines possess. Although speculative, it is possible the purines play a role in regulating blood flow by producing vasodilation. ATP, for example, can cause vasodilation by releasing an endothelium-derived relaxing factor (EDRF) (De Mey et al., 1981) and an endothelium-derived hyperpolarizing factor (EDHF) (Chen et al., 1991) from vascular endothelial cells. Adenosine, released as such and that formed by the metabolism of adenine nucleotides, can cause vasodilation by acting on P1 purinoceptors on vascular smooth muscle (Ribeiro et al., 1985 ; Burnstock, 1987). Both adenine nucleotides and nucleosides can reduce the depolarization-induced release of sympathetic nerve neurotransmitters and thus limit vasoconstriction (Katsuragi et al., 1990). These substances possess a number of actions that could contribute to vasodilation. Therefore, ATP and its metabolites from vascular endothelium may participate in the local regulation of blood flow and control the blood pressure.

\section{Acknowledgments}

This work was supported in part by a Grant-in-Aid for Scientific Research from the Ministry of Education, Science, Sports and Culture.

\section{References}

Bodin, P., Bailey, D. and Burnstock, G. (1991). Increased flow-induced ATP release from isolated vascular endothelial cells but not smooth muscle cells. Br. J. Pharmacol. 103 : 1203-1205.

Burnstock, G. (1987). Local control of blood pressure by purines. Blood Vessels 24: 156-160.

Chen, G. and Suzuki, H. (1991). Endothelium-dependent hyperpolarization elicited by adenine compounds in rabbit carotid artery. Am. J. Physiol. 260: H1037-H1042.

De Mey, J.G. and Vanhoutte, P.M. (1981). Role of the intima in cholinergic and purinergic relaxation of isolated canine femoral arteries. J. Physiol. (London) 316: 347-355.

Gordon E.L., Pearson J.D., Slakey L.L. (1986). The hydrolysis of extracellular adenine nucleotides by cultured endothelial cells from pig aorta. J. Biol. Chem. 261: 15496-15504.

Gordon E.L., Pearson J.D., Dickinson E.S., Moreau D., Slakey L.L. (1989). The hydrolysis of extracel- 
lular adenine nucleotides by arterial smooth muscle cells: regulation of adenosine production at the cell surface. J. Biol. Chem. 264: 18986-18992.

Hashimoto, M., Ishinaga, Y., Honda, M., Ohoka, M., Morioka, S. and Moriyama, K. (1991). Agerelated increase in the uptake of acetylated low density lipoprotein into cultured endothelial cells from rat aorta. Exp. Gerontol. 26 : 397-406.

Hashimoto, M., Hara, T., Honda, M., Ishinaga, Y., Moriyama, K. and Masumura, S. (1992). Metabolic aspects of endothelial cells cultured from rat aortae. Artery 19: 284-296.

Ishii, R., Shinozuka, K., Kobayashi, Y., Hattori, T., Hashimoto, K. and Takeuchi, K. (1993). Methoxamine enhances the release of endogenous noradrenaline from rabbit ear artery: possible involvement of ATP. Naunyn-Schmied. Arch. Pharmacol. 348: 46-52.

Katsuragi, T., Tokunaga, T., Usune, S., Furukawa, T. (1990). A possible coupling of postjunctional ATP release and transmitters' receptor stimulation in smooth muscle. Life, Sci. $46: 1301$ 1307.

Milner, P., Bodin, P., Loesch, A. and Burnstock, G. (1990). Rapid release of endothelin and ATP from isolated aortic endothelial cells exposed to increased flow. Biochem. Biophys. Res. Comm. $170: 649-656$.

Mohri, K., Takeuchi, K., Shinozuka, K., Bjur, R.A. and Westfall, D.P. (1993). Simultaneous determination of nerve-induced adenine nucleotides and nucleosides released from rabbit pulmonary artery. Anal. Biochem. 210: 262-267.

Ohoka, M., Honda, M., Morioka, S., Ishikawa, S., Nakayama, K., Yamori, Y. and Moriyama, K. (1990). Effects of E-1020, a new cyclic AMP-specific phosphodiesterase inhibitor, on cyclic AMP and cytosolic free calcium of cultured vascular smooth muscle cells. Jpn. Circ. J. 54 : 679-687.

Ribeiro, J.A. and Lima, M.S. (1985). The hypotensive effect of intracarotid injections of adenosine triphosphate depends on its hydrolysis to adenosine. Pharmacol. Res. Comm. 17 : 155-260.

Ross, R. (1971). The smooth muscle cell. II. Growth of smooth muscle in culture and formation of elastic fibers. J. Cell. Biol. 50 : 172-186.

Ryan, U.S., Mortara, M and Whitaker, C. (1980). Methods for microcarrier culture of bovine pulmonary artery endothelial cells avoiding the use of enzymes. Tissue \& Cell 12: 619-635.

Sedaa, K.O., Bjur, R.A., Shinozuka, K. and Westfall, D.P. (1990). Nerve and drug-induced release of adenine nucleosides and nucleotides from rabbit aorta. J. Pharmacol. Exp. Ther. 252 : 10601067.

Shinozuka, K., Sedaa, K.O., Bjur, R.A. and Westfall, D.P. (1991). Participation by purines in the modulation of norepinephrine release by methoxamine. Eur. J. Pharmacol. 192: 431-434.

Slakey L.L., Gordon E.L. (1990). A comparison of ectonucleotidase activities on vascular endothelial and smooth muscle cells. In: Dubyak G.R., Fedan J.S., eds. Biological Actions of Extracellular ATP. Ann. NY Acad. Sci. 603: 366-379.

Westfall, D.P., Sedaa, K.O. and Bjur, R.A. (1987). Release of endogenous ATP from rat caudal artery. Blood Vessels 24 : 125-127. 